\title{
HusSerL, Edmund. I ntroducción a la ética. Edición de Mariana Chu, Mariano Crespo y Luis Rabanaque, Trotta: Madrid, 2020, 364 páginas
}

\author{
Noé Expósito Ropero \\ SEFE \\ noe.filo@hotmail.com
}

La excelente traducción española de estas importantes lecciones de Introducción a la ética, a cargo de Mariana Chu, Mariano Crespo y Luis R. Rabanaque, publicada en una cuidada edición en la editorial Trotta, consolida una feliz etapa en lo que a la recepción de Husserl en lengua hispana se refiere. Tras la reciente reedición en la editorial Alianza de la traducción que en 1994 publicaron Javier San Martín y César Moreno de los Problemas fundamentales de la fenomenología, precedida, a su vez, por la publicación en la editorial Sígueme de los Textos breves (1887-1936), proyecto coordinado por Agustín Serrano de Haro y Antonio Zirión, en el que han participado más de una decena de reconocidos especialistas de uno y otro lado del Atlántico, esta Introducción a la ética, impartida por Husserl en 1920 y 1924 en la Universidad de Friburgo, puede ser leída por vez primera en nuestra lengua y, lo que no es menos importante, enmarcada en su amplio y complejo trasfondo filosófico, fruto de más de dos décadas de intensa investigación fenomenológica teórica y práctica.

Como nos recuerda Mariana Chu en su brillante “Presentación" (pp. 9-34), el origen de estas lecciones, recogidas en el tomo XXXVII de Husserliana, Einleitung in die Ethik. Vorlesungen Sommersemester 1920 und 1924, editado y publicado en 2004 por Henning Peucker, se remonta a las Vorlesungen über Ethik und Wertlehre de 1908-1914, editadas y publicadas en 1988 por Ullrich Melle en el tomo XXVIII de la misma colección, pues es en estas lecciones tempranas donde Husserl, escribe Mariana Chu, "sienta las bases de los primeros niveles de una ética pura, la axiología y la práctica formales" (p. 16). Sin poder entrar aquí en 
los pormenores técnicos que nos muestran, por un lado, la continuidad entre las lecciones sobre ética de 1908-1914 y las de 1920-1924 -recuérdese, por ejemplo, el importante papel que seguirán jugando las leyes axiológicas de "sumación" y de "absorción", centrales tanto en estas últimas como en los artículos de Kaizo (1923-1924) - , y, por otro, la reformulación, incluso el rechazo, de algunos principios básicos asumidos en la etapa temprana - véase, por ejemplo, la crítica al imperativo categórico de su maestro Franz Brentano, del cual nos dice Husserl en estas lecciones que "no es suficiente el obrar «según la mejor ciencia y conciencia»; actuar así no es sin más actuar moralmente" (p. 249)—, lo que nos interesa destacar aquí de este tránsito es que, como bien señala Mariana Chu, “sin romper con las lecciones de la preguerra, sino modificándolas a la luz de los análisis genéticos, en las lecciones que aquí presentamos, el acento pasa de una fundación de validez centrada en la objetividad de las leyes axiológicas y prácticas a una fundación genética de la ética centrada en el concepto de persona y del telos de una vida ética" ( p. 20). Este es, efectivamente, el hilo conductor que nos muestra la coherencia interna del desarrollo de la ética husserliana, desde las primeras lecciones de 1908-1914 hasta los escritos recogidos en el tomo XLII de Husserliana, publicado en 2014 a cargo de Rochus Sowa y Thomas Vongehr, concretamente, en la cuarta parte (pp. 265-530), dedicada a la "ética tardía" (späte Ethik), donde Husserl, en continuidad con los planteamientos anteriores, nos lega una serie de textos que atestiguan el tipo de temas y problemas en los que desemboca su reflexión ética: "Valores personales y valores materiales. Amor en sentido auténtico. Valores individuales absolutos y valores relativos. Sacrificio de valores y absorción de valores" (texto 23); "Las decisiones de valor y la llamada que se dirige al yo. Conflictos de valor y sacrificio de valor" (texto 25); "Lo absolutamente debido en el desarrollo de la humanidad y en la vida del individuo. El nuevo imperativo categórico" (texto 27). En este sentido, como bien apunta Mariana Chu, las lecciones de Introducción a la ética que aquí presentamos "hacen las veces de bisagra entre la ética formal del periodo de Gotinga y los textos de orden metafísico, es decir, relativos a la facticidad, en los que se aborda la posibilidad de una existencia auténtica" (p. 9).

Así, teniendo presente el trasfondo y el desarrollo completo de la ética husserliana, adentrémonos ya en estas lecciones de 1920-1924. No es mi objetivo aquí, ni resulta posible, ofrecer una exposición detallada del contenido de las mismas, sino, sencillamente, comentar algunas $-y$ solo algunas- de las ideas 
principales de esta obra fundamental del siglo XX, para invitar al lector a sumergirse en su lectura. De los diez capítulos que componen este curso, a los que Husserl añade el importante excurso “Naturaleza y espíritu” (pp. 259-313) ${ }^{1}$, además de un total de veintidós "anexos" o "textos complementarios", es en el primero de ellos, dedicado a la "Determinación y delimitación sistemático-introductorias del concepto de ética" (pp. 37-62), donde encontramos sintetizadas las tesis básicas que Husserl venía elaborando desde sus cursos de 1908-1914 sobre Ética y teoría del valor. Se trata, por tanto, del capítulo más sistemático de estas lecciones, compuesto de cinco epígrafes, en los que Husserl delinea, en primer lugar, su idea de "La ética como disciplina técnica universal de los fines correctos que dirigen la acción y de las leyes normativas superiores" (pp. 37-42), así como la "delimitación de la ética y la moral" y "la diferencia entre ética individual y ética social” (pp. 44-47), para, ya en el tercer epígrafe, abordar el problema del criterio de la "distinción entre disciplinas técnicas y ciencias teóricas" en diálogo crítico y directo con la delimitación establecida por su maestro, Franz Brentano, entre “interés teórico" e “interés práctico" (pp. 47-52). El resultado de esta revisión crítica de las tesis de Brentano se nos ofrece en el quinto epígrafe, en el que Husserl, en continuidad con sus planteamientos tempranos, postula "la necesidad de una separación de la investigación orientada de modo puramente teórico de la orientada de modo práctico" y, conforme a ella, "la idea de una lógica y de una ética puras" (pp. 56-62). Merece la pena citar las líneas finales de este primer capítulo, pues será a partir de estas ideas desde donde Husserl emprenda la revisión crítica de la historia de la ética clásica y contemporánea: “Así como la lógica pura, que, con sus disciplinas referidas al conocimiento, a la verdad y a la objetualidad sobrepasa los confines de la lógica tecnológica y, en cuanto teoría de los principios, abraza a todas las ciencias imaginables, así la ética pura, que

1 Tal y como nos indican los editores (p. 160, nota 7), este importante excurso, cuyo título completo reza "Naturaleza y espíritu. Ciencias objetivas y ciencias normativas. Ciencias de la naturaleza y ciencias del espíritu", aparece en el trascurso de la séptima lección, dedicada, como veremos, a la polémica entre los moralistas del entendimiento y los moralistas del sentimiento en el siglo XVII (pp. 145-184), concretamente, en el parágrafo treinta, sobre "La diferencia entre leyes materiales y leyes normativas en cuanto leyes racionales". Puesto que no podemos dedicarle aquí la atención que merece, nos remitimos al precoz estudio de Javier San Martín, “Ética, antropología y Filosofía de la Historia. Las Lecciones de Husserl de Introducción a la ética del semestre de verano de 1920", en Isegoría, 5, 1992, pp. 43-77, donde se ocupa amplia y detalladamente de este excurso. Este estudio, publicado con más de una década de antelación a la aparición del tomo XXXVII de Husserliana en 2004, merecería ser tenido muy en cuenta por los estudiosos de la ética de Husserl, sobre todo en nuestra lengua. 
le es paralela, abraza, con sus disciplinas dirigidas al querer racional, a las legítimas proposiciones morales y a los auténticos bienes prácticos, el universo de la posible praxis, según los sujetos, los ordenamientos jurídicos, los bienes, y las relativas organizaciones prácticas" (p. 62).

Así, en el segundo capítulo, “Las posiciones fundamentales de la ética de la Antigüedad y un panorama de la ética moderna" (pp. 63-76), Husserl se ocupa, en primer lugar, del escepticismo de los sofistas en el inicio de la historia de la ética, para, a continuación, exponer "la reacción de Sócrates contra la sofística", gesto que, para el fenomenólogo, "inaugura una ética científica". Tal es, como se recuerda, la tesis básica que Husserl desarrolla en otro texto clave de esta época, "La idea de una cultura filosófica. Su primera germinación en la filosofía griega" (1923), así como en los citados artículos de Kaizo. La crítica central de Husserl a la sofística y al hedonismo antiguo apunta a "su falta de diferenciación entre preguntas de hecho y preguntas de derecho" (68-72), critica que, aplicada ya a la ética moderna, extiende al "empirismo ético", puesto que este enfoque, sostiene Husserl, "ve en las ideas normativas solo expresiones para hechos, para facticidades del juzgar, sentir, querer del ser humano y, de acuerdo con ello, ve en los principios normativos leyes de hechos, las que, en consecuencia, se enmarcan en las de la antropología, biología, psicología", concluyendo que, "en la medida en que en esto se toma aquí en consideración principalmente a la psicología, el empirismo se llama también psicologismo" (p. 73).

De este modo, siguiendo el programa anunciado al final de este segundo capítulo, Husserl dedica el tercero a "La ética y la filosofía del Estado de Hobbes y su principio egoísta de la autoconservación" (77-88), en el que, a pesar de rechazar su teoría, asume "el valor de un significativo experimento teórico", puesto que Hobbes nos ofrecería "el primer ensayo, aún unilateral, de la construcción de una socialidad racional", ya que en ella "podemos ver qué idea de Estado exigiría la razón práctica si el ser humano fuese de hecho un ser simplemente egoísta” ( p. 83). De acuerdo con ello, se pregunta Husserl, “¿no se podría considerar de manera semejante y a priori qué formaciones sociales, qué idea de Estado exige la razón práctica si basáramos la investigación sobre la esencia plena del ser humano en su complejidad, en pura universalidad?" (ib.). Tal es, justamente, la hipótesis que investiga en el último epígrafe de este capítulo, "La idea de una mathesis formal de la socialidad a partir de Hobbes" (pp. 85-87). 
En los dos capítulos siguientes, el cuarto y el quinto, dedicados a la "Discusión crítica con la ética hedonista: el hedonismo como escepticismo ético" (p. 89-108) y a la exposición crítica de "El hedonismo como egoísmo en algunas posiciones de la ética moderna" (pp. 109-124), Husserl profundiza en su crítica de este enfoque, objetándole "la confusión de la diferencia entre valorar y valor", frente a la cual reivindica "la necesidad del análisis fenomenológico de la conciencia desiderativa y valorativa para una ética filosófica" ( pp. 96-103), así como de un análisis preciso de "la cuestión de la racionalidad de la motivación de acto", entendiendo "los valores como motivos en los actos de la voluntad" (pp. 103-108). Desde este planteamiento abordará, ya en el quinto capítulo, "el subjetivismo ético extremo de Stirner y su crítica" (pp. 111-115), así como “las teorías egoístas en ética", diferenciando dos tipos de estas teorías: "un tipo está representado por Hartley y el utilitarismo inglés que parte de él, y que, en el siglo XIX, tiene en el joven Mill su representante más conocido", mientras que "el otro tipo de teorías está representado por los materialistas franceses como La Mettrie y, sobre todo, Helvétius, quien, con una motivación abiertamente egoísta, deriva las virtudes morales del egoísmo, es decir, rechaza el altruismo real" (pp. 116-117). Finalmente, en el último epígrafe de este capítulo, Husserl expone su crítica a "la fundamentación psicológico-asociacionista del utilitarismo altruista", planteando, así, el tema del sexto capítulo, dedicado a "Las legalidades peculiares del desarrollo del ser espiritual. El reino de la motivación" (pp. 125-144), en el que, refiriéndose a Dilthey, reivindica la diferencia entre "explicar y comprender", para mostrar que "la psicología naturalista desconoce lo esencialmente propio de lo espiritual y de su génesis" (pp. 125-129). En este sexto capítulo, al igual que en el primero, Husserl traza algunas distinciones sistemáticas básicas, tales como "la diferencia entre motivación racional e irracional" (pp. 129-131), o la tesis clave según la cual "las motivaciones activas y los actos del yo están sujetos a las cuestiones de la justificación racional" (pp. 131-134), para mostrar, por un lado, "el fracaso de la psicología asociativa naturalista respecto a las cuestiones de razón" (pp. 134-138) y, por otro, "la absurda naturalización de lo espiritual debida a la imitación de la ciencia natural" (pp. 138-143). Tales son las problemáticas que Husserl analizará, apoyándose en estos planteamientos, en los dos capítulos siguientes, el séptimo, dedicado a "La polémica entre los moralistas del entendimiento y los moralistas del sentimiento en el siglo XVII" (pp. 145-184), y el octavo, centrado en “La filosofía moral empirista de Hume” (pp. 185-208), cuya crítica sintetiza Husserl en los siguientes puntos: primero, en "la 
naturalización de la vida de la conciencia"; segundo, en su "errada interpretación psicológico-asociativa de la intencionalidad de la esfera del sentimiento y de la voluntad"; tercero, en "el desconocimiento de las leyes esenciales de la razón axiológica y práctica"; cuarto, en "la errada interpretación de la legalidad de la motivación" (pp. 190-202).

Mención aparte merece también "la ética kantiana de la razón pura", a la que Husserl dedica el noveno capítulo (209-246), cuya crítica, al igual que en el caso de Hume, se nos resume en los siguientes puntos: primero, en los "problemas de la voluntad pura y de la validez de la voluntad en el trasfondo de una fenomenología de la voluntad"; segundo, en "la posibilidad, pasada por alto por Kant, de una determinación de la voluntad por objetividades ideales"; tercero, en su desconocimiento de "las legalidades esenciales a priori de la esfera del sentimiento y de la sensación"; y, cuarto, en el análisis de "las verdades esenciales captadas en el puro ver como el sentido auténtico de lo a priori" (pp. 219-231). Con todo, y a pesar su crítica, Husserl reconoce "el meritorio empeño de Kant por una auténtica moral basada en una libre posición autónoma", de su "Iucha contra el hedonismo en cuanto enemigo principal de una ética auténtica", así como "la idea del hombre verdadero y de la verdadera comunidad humana como fin de una forma universal de vida ética", tal y como queda expuesto en los dos últimos epígrafes de este capítulo (pp. 236-245). Tales ideas son, junto a las tesis análogas de Fichte sobre el ideal de humanidad, las que inspiran el último capítulo de estas lecciones, en el que Husserl nos ofrece, como adelantamos al comienzo, un "Panorama de una ética de la mejor vida posible instituida sobre la voluntad" (pp. 247-258). Allí, tras exponer "la diferencia entre la actitud axiológica y la actitud ética", Husserl reivindica, frente a la vida ingenua, la exigencia una vida auténtica en la evidencia ética, en la cual "cada uno de nosotros dice: yo, yo quiero vivir mi vida, mi vida entera, de ahora en adelante, en todos sus actos y con todo el contenido de vivencias, de modo tal que sea mi mejor vida posible; mi mejor vida posible, es decir, la mejor posible que yo pueda. Esta es para mí la vida debida y absolutamente debida" (p. 254). Valga, pues, esta breve y sumarísima presentación de estas lecciones de Husserl para invitar al lector a sumergirse en ellas, pues estamos, sin ninguna duda, ante uno de las obras más importantes que sobre ética nos ha legado, no solo el fundador de la fenomenología, sino todo el siglo XX. 